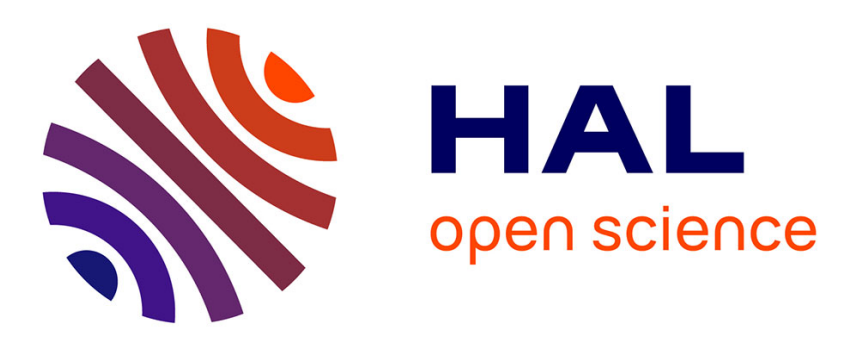

\title{
THEORY OF MOLECULAR LASER EMITTING IN Mid-IR REGION AND UTILIZING SINGLET OXYGEN ENERGY
}

\author{
V. Kochelap, V. Datsyuk, I. Izmailov
}

\section{- To cite this version:}

V. Kochelap, V. Datsyuk, I. Izmailov. THEORY OF MOLECULAR LASER EMITTING IN Mid-IR REGION AND UTILIZING SINGLET OXYGEN ENERGY. Journal de Physique IV Proceedings, 1991, 01 (C7), pp.C7-659-C7-662. 10.1051/jp4:19917176 . jpa-00250854

\section{HAL Id: jpa-00250854 https://hal.science/jpa-00250854}

Submitted on 1 Jan 1991

HAL is a multi-disciplinary open access archive for the deposit and dissemination of scientific research documents, whether they are published or not. The documents may come from teaching and research institutions in France or abroad, or from public or private research centers.
L'archive ouverte pluridisciplinaire HAL, est destinée au dépôt et à la diffusion de documents scientifiques de niveau recherche, publiés ou non, émanant des établissements d'enseignement et de recherche français ou étrangers, des laboratoires publics ou privés. 


\title{
THEORY OF MOLECULAR LASER EMITTING IN Mid-IR REGION AND UTILIZING SINGLET OXYGEN ENERGY
}

\section{V.A. KOCHELAP, V.V. DATSYUK* and I.A. IZMAILOV}

Inst. of Semiconductors, Academy of Sci. of the Ukr. SSR, Pr. Nauka 45, Kiev 252650, USSR

${ }^{*}$ Kiev State University, Dep. Phys./Theor. Phys., Vladimirskaya 64, Kiev 252017, USSR

\begin{abstract}
A theoretical analysis is made of the kinetics of inverted population of $\mathrm{SO}_{2}$ levels in a mixture containing vibrationally excited oxygen $O_{2}(x, v)$, formed as a result of relaxation of the $o_{e}{ }^{1} \Delta^{\prime}$ electronic energy. It is shown that the gain for the $\mathrm{SO}_{2}$ transitions at the 12 and $16 \mathrm{~km}$ wavelengths is sufficient to achieve lasing.
\end{abstract}

\section{1. - Introduction.}

At present, chemical singlet oxygen generators have been developed, characterized by the highly efficient formation of electronically excited $\mathrm{O}_{2} \mathrm{Ca}{ }^{1} \Delta_{8} \mathrm{molecules} / 1 /$. It was established in Refs. 2 and 3 that as a result of the deactivation of a single $0_{2} C^{1} \Delta$ molecule, five vibrational quantia of oxygen are formed in the ground electronic state,

$$
\left.\left.\left.\left.o_{2} c^{1} \Delta, v^{\prime}=0\right)+0_{2} c^{3} \Sigma, v=0\right) \rightarrow O_{2} c^{3} \Sigma, v=n\right)+0_{2} c^{3} \Sigma, v=5-n\right)(1)
$$

where $n=0,1$, and 2 . Therefore, gaseous $0_{2} c x{ }^{3} \sum_{8}^{-}$can be obtained at pressures up to 10 Torr with high $(1 \div 2 \mathrm{kK}, \mathrm{v}$ vibrational and 10 w C $300 \mathrm{KJ}$ translational temperatures. The high vibrational energy stored in $O_{2}(X$, w may be utilized to obtain lasing in the middle infrared by transfer of vibrational excitation to optically active molecules.

In this paper we give a theoretical background for the development of new mid-IR laser system utilizing the singlet oxygen energy. We propose to use the $0_{2} C^{1} \Delta^{2}$ energy by the following two steps. During the first one the $0_{2} c^{1}{ }^{3}$ electronic energy should be converted into the vibrational energy of the $o_{2}\left(x^{a_{\Sigma_{g}}}\right)$ molecules. During the second step excitation and inverted population of vibrational levels of active molecular acceptor $C \mathrm{SO}_{2} 2$ can arise as a result of $V V$, VV' and VT processes. 


\section{2. $-\mathrm{O}_{2} \mathrm{C}^{1} \Delta$ electronic energy conversion into the $o_{2}(x$, v vibrational energy.}

The kinetics of the formation of vibrationally excited $o_{2}(x, v)$ may be investigated taking into account not only process (1) but also the VT relaxation. Numerical calculations show that an appreciable rraction of the $O_{2} C^{1} \Delta$ electronic energy is converted into the $O_{2}(x, v)$ vibrational energy at temperatures $T$ below $300 \mathrm{~K}$. For example, when $T \leq 250 \mathrm{~K}$, the efficiency of conversion of the $\mathrm{O}_{2} \mathrm{C}^{1} \Delta \mathrm{J}^{\mathrm{electronic}}$ energy into the vibrational energy reaches 0.2 , and when $T \leq 160 k$, it becomes 0.6 . The vibrational temperature of $O_{2}(X$, $w)$ may then be $1.5 \div$ 2. $5 \mathrm{kK}$, depending on the degree of electronic excitation of the oxygen. It is suggested that the vibrationally excited $o_{2}$ produced can be used as a vibrational energy reservoir in a laser where $O_{2}(X, v)$ is mixed with optically active $\mathrm{SO}_{2}$ molecules.

\section{3. - Kinetics of formation of active medium.}

The energy levels of $\mathrm{O}_{2}$ and $\mathrm{SO}_{2}$ and also the basic vibrational relaxation processes are shown in Fig.1. The kinetics of energy relaxation in an $\mathrm{O}_{2} \mathrm{C}^{1} \Delta^{\mathrm{O}-\mathrm{O}_{2}}-\mathrm{SO}_{2}-\mathrm{O}_{3}$ mixture was first studied experimentally in Ref.2. It was established that $\mathrm{SO}_{2}$ molecules do not interact with $\mathrm{O}_{2} \mathrm{C}^{1} \mathrm{~S}$ but have an appreciable influence on the relaxation kinetics of the vibrationally excited $O_{2}(X)$.

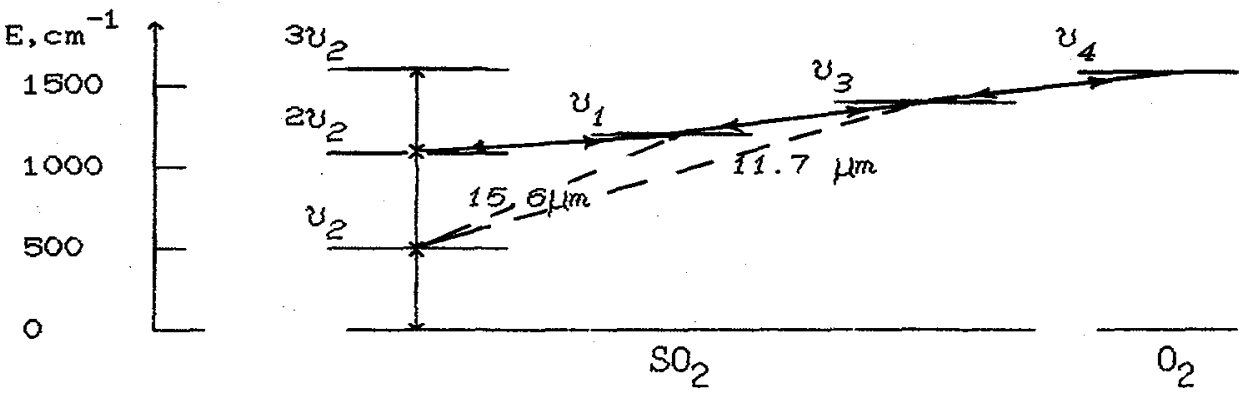

Fig.1. Lowest vibrational levels of $\mathrm{SO}_{2}$ and $\mathrm{O}_{2}$ molecules.

The solid arrows indicate the way of the energy transfer and the dashed arrows indicate the laser transitions.

The vibrational relaxation mechanism in an $\mathrm{O}_{2}-\mathrm{SO}_{2}$ mixture was studied in Refs. 4 and 5. Measurements were made of the times of the main VT and $V V$ ' exchange processes. The intramode VV exchange in SO, is the fastest process and results in the establishment of a quasi equilibrium distribution of molecules over vibrational levels with a vibrational temperature $T_{i} C i$ is the mode numbers. The EV exchange 
time in the process ( 1 ) is much longer than the times of the ' $V V^{\prime}$ exchange between $\mathrm{O}_{2}\left(v_{4}\right)$ and $\mathrm{SO}_{2}\left(v_{3}\right)$, intermode exchange in $\mathrm{SO}_{2}$, and VT relaxation of $\mathrm{SO}_{2}\left(v_{2}\right)$. Consequently, in order to obtain lasing on the $\mathrm{SO}_{e}$ vibrational transitions, $\mathrm{SO}_{2}$ must be mixed with excited $\mathrm{O}_{2}$ molecules after completion of process (1).

\section{4. -Population inversion and 1 ight gain on $\mathrm{SO}_{2}$ vibrational transitions.}

We have investigated the kinetics of formation of the active medium after $\mathrm{mixing}$ of $\mathrm{O}_{2}$ and $\mathrm{SO}_{2}$. The instantaneous mixing approximation has been used. The time dependencies of the $T_{i}$ have been computed from the rate equations $/ 6$, which describe the one- and two- quanta 'VV' exchange, and VT-relaxation. The change of $T$ has been also taken into account. It was found that the inverted population of the $\mathrm{SO}_{2}$ vibrational levels arises at a translational temperature of the mixture substantially lower than $300 \mathrm{~K}$. Calculations were made for the case when before mixing the vibrational temperature of $\mathrm{O}_{2}(X, v)$ is $\mathrm{T}_{4}=$ $1.5 \mathrm{kK}$, the oxygen is cooled to $T=77 \mathrm{~K}$ and its pressure equals 10 Torr. A gas with these parameters can be obtained by cooling a mixture containing $10 \% \mathrm{O}_{\mathrm{e}} \mathrm{C}^{\mathrm{B}} \Delta^{\mathrm{S}}$ in a time much shorter than the VT relaxation time of $\mathrm{O}_{2}(x, w)<\tau_{v r}=1 \div 10 \mathrm{~s}$ ). The $\mathrm{SO}_{2}$ parameters berore mixing were assumed to be as follows: $T=200 \mathrm{k}$, pressure $1 \div 2$ Torr.
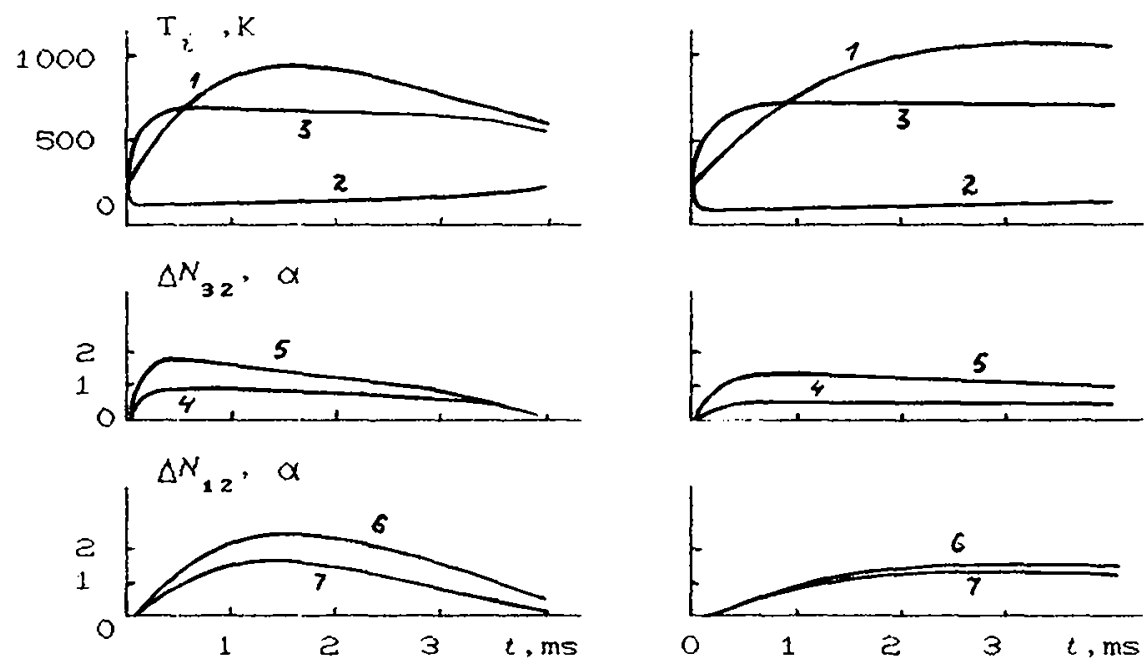

$\propto$

๖

Fig.2. Time dependences of $T_{1}(1), I_{2}(2), T_{3}(3)$, $\Delta N_{32}-5 \cdot 10^{15} \mathrm{~cm}^{-3}(4), \alpha\left(\lambda=12 \mu(m), 10^{-3} \mathrm{~cm}^{-1}(5)\right.$, $\Delta N_{12}^{32}-5 \cdot 10^{15} \mathrm{~cm}^{-3}(6), \alpha(\lambda=16 \mu \mathrm{m}) \cdot 10^{-4} \mathrm{~cm}^{-1}(7)$,

at $\mathrm{SO}_{2}$ pressures before mixing of $2(\alpha)$ and 1 Torr (b). 
The results of the calculations are plotted in Fig.2. It can be seen that after mixing of $\mathrm{SO}_{2}$ and $\mathrm{O}_{2}$, the stretching vibrational modes of $\mathrm{SO}_{2}$ are populated, and $\mathrm{T}_{1}, \mathrm{~T}_{3} \gg \mathrm{T}_{2} \simeq \mathrm{T}$. The population densities $\Delta N_{i 2}$ of the stretching $C i=1,3$, and bending modes have been calculated,

$$
\left.\left.\Delta N_{i 2}=\left[S_{2}\right] z_{v}^{-1}\left[\exp r-\vartheta_{i} / T_{i}\right]-\exp r-\vartheta_{2} / T_{2}\right]\right] .
$$

Here $\theta_{i}$ is the characteristic temperature of the $i$ th mode, $z_{v}$ is the vibrational statistical sum. The equations from Ref. 6 were used to calculate the optical gains for $001 \rightarrow 010 \mathrm{C} \lambda=11.8 \mu \mathrm{m}$ and $100 \rightarrow 010$ $c \lambda=15.8 \mu \mathrm{m})$ vibrational-rotational transitions:

$$
\alpha=\sigma_{i 2} \Delta \Delta_{i 2}
$$

where $\lambda$ is the wavelength; the quantum number of the tatal rotational

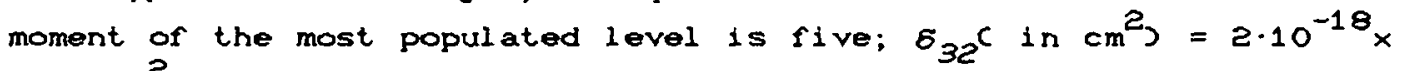
$(200 /)^{2} H(\alpha, 0)$; $H(\alpha, 0)$ is the Voigt function $7 /$; according to the estimates $\sigma /, \sigma_{12}$ is 50 times smaller than $\sigma_{32}$.

It can be seen from Fig. a that the inversion densities $\Delta^{N} 32=$ $(2 \div 5) \cdot 10^{15} \mathrm{~cm}^{-8}$, and $\Delta N_{12}=10^{16} \mathrm{~cm}^{-9}$ is maintained for several milliseconds. The gain at $\lambda=11.8 \mu \mathrm{m}$ is $(1+2) \cdot 10^{-3} \mathrm{~cm}^{-1}$. The gain at $15.8 \mu \mathrm{m}$ is higher than $10^{-4} \mathrm{~cm}^{-1}$. The main reason for the loss of the inverted population is heating of the medium that results in flliing of the lower laser level. The rate of this heating grouths when $T$ increases.

\section{5. -Concl usions.}

Singlet axygen generators make it possible to build a low-temperature continuous-flow molecular laser emitting in the mid-IR spectral region. It is shown that ow lasing at wavelengths of 12 and $16 \mu \mathrm{m}$ can be achieved in $\mathrm{O}_{2}-\mathrm{SO}_{2}$ mixtures by using of the $\mathrm{O}_{2} \mathrm{C}^{1} \Delta^{3}$ energy.

\section{$R e r e r e n c e s$}

1/ APS Study: Science and Technology of Directed Energy Weapons, Rev. Mod. Phys., 1987, v. 59, N 3, p. S33 - S67.

2/ PARKER, J, G, J. Chem. Phys. 67 (1977) 5352.

3/ WILD,E, KLINGSHIRN, $H$, et. ai. , Chem. Phys. Lett. 93 (1982) 490.

/4/ ANDERSON, B, SHIELDS, F, D, and BASS, H, E, J. Chem. Phys. 56 (1972) 1147.

S/ WEST, G, A, WESTON, R, E, Jr. , and FLYNN, G, W, J. Chem. Phys. 67 C1977) 4873.

6/ VOLKOV, A, YU, DEMIN, A,I, and KUDRY AVTSEV, E, M, Preprint $N 3$ Cin Russion, Lebeder Physics Institute, Academy of Sciences of the USSR, Moscow (1980).

$7 /$ LOSEV,S, A, Gasdynamic Lasers, Springer Series in Chemical Physics 12. Springer-Verl and, Berlin (1981). 